\title{
Нефедов Сергей Трофимович
}

Санкт-Петербургский государственный университет,

Россия, 199034, Санкт-Петербург, Университетская наб., 7-9

s.nefedov@spbu.ru

\section{Варьирование оценки в коммуникативных практиках научного дискурса}

Для цитирования: Нефедов С.Т. Варьирование оценки в коммуникативных практиках научного дискурса. Вестник Санкт-Петербургского университета. Язык и литература. 2021, 18 (4): 760-778. https://doi.org/10.21638/spbu09.2021.408

Статья представляет комплексный анализ языка оценок как прагматического инструмента в структуре профессиональной научной деятельности лингвистов. Актуальность работы заключается в ее включенности в современные междисциплинарные исследования языковых ресурсов с позиций лингвистической прагматики, интеракциональной социолингвистики и лингвистики дискурса, ориентированных в целом на изучение языка и интерпретацию значений языковых единиц в реальных социальных контекстах при учете широкого спектра экстралингвистических факторов. Актуальной с позиций современной лингвистики является и лингводискурсивная составляющая данного исследования, которая дает возможность рассматривать оценочно-квалифицирующую, институционально обусловленную деятельность субъектов научного дискурса на транстекстовом уровне в непосредственной погруженности в практику использования языка оценок. Научная новизна проведенного анализа заключается в следующих результатах: установлено функционально-коммуникативное варьирование языка оценок в зависимости от центральной задачи научно-исследовательской, научно-экспертной и научно-обучающей коммуникативных практик, направленных соответственно на представление и обоснование нового научного результата, его профессиональную экспертизу и трансфер наличного знания при обучении основам теоретических дисциплин; предложена дисциплинарно соотнесенная классификация оценок с выделением познавательных эпистемических, экспертных и персуазивных оценок; обоснованы сущностные отличия выделенных типов оценок в прагматических категориях автороцентричности, нормоцентричности и адресатоцентричности; показана тексто- и дискурсообразующая роль персуазивных оценок важности/релевантности в профилировании и выдвижении в фокус внимания устоявшегося знания и в структурировании научно-учебного текста. Материалом исследования послужили немецкоязычные корпусы журнальных статей, научных рецензий и вузовских учебников по лингвистике. Процедура анализа включает структурную сегментацию текстов на предикации, выделение оценочно заряженных предикаций и рассмотрение употребленных в них оценочных средств на основе прагма-семантических методов, среди которых центральную роль в интерпретации функционального потенциала оценок сыграли контекстуальные методы и корпусные статистические подсчеты.

Ключевые слова: оценка, научный дискурс, эпистемическая познавательная оценка, экспертная оценка, персуазивная оценка.

() Санкт-Петербургский государственный университет, 2021 
...иценка, порожденная желанием, отлична и от оиенки, вытекающей из долга, и от оиенки, вызванной нуждой.

Н. Д. Арутюнова. Типь языковых значений

\section{Постановка проблемы}

Язык оценок представлен в настоящей статье с точки зрения процессуальной динамики и институциональной адресованности. Это означает, что в фокусе внимания находятся закономерности контекстно обусловленного формирования оценочных смыслов при решении стоящих перед субъектами дискурса личных и коллективных задач. Исходя из этого, функциональный потенциал оценочных высказываний интерпретируется как отражение научно-исследовательской, научно-экспертной или научно-обучающей активности дискурсивных субъектов, ориентирующихся при выборе оценочных средств на ведущую задачу соответствующей коммуникативной практики. В этом смысле оценка трактуется как лингвосемиотический и прагматический ресурс интеграции участников дискурса в научную деятельность и как сигнал их включенности в академическое профессиональное сообщество с его общими интересами и целями.

Внешний экстралингвистический фон употребления оценочных средств категоризируется в предпринятом анализе через понятие «коммуникативная практика». Именно данное понятие позволяет наиболее полно описать коммуникативно-деятельностный аспект оценивания в тесной сопряженности и под влиянием внешней ситуации общения. В прагма- и социолингвистических исследованиях под коммуникативной практикой понимается «срез социальной действительности», воплощающий устойчивый, постоянно воспроизводимый в коммуникации тип деятельности взаимодействующих акторов с целью решения одинаковых или сходных задач [Gansel et al. 2019: 1-9; Чернявская 2021: 12]. Многообразные параметры коммуникативной практики составляют в своей совокупности широкий социокультурный контекст, с учетом которого транслируются и интерпретируются значения языковых выражений в их реальном употреблении [Нефедов, Чернявская 2020; Nefedov 2020]. В этой теоретической проекции коммуникативно-речевые акты оценивания рассматриваются как неотъемлемая составляющая научных коммуникативных практик, отражающая посредством разных конфигураций оценочно-квалифицирующих действий взаимодействие знания «старого» и «нового», предлагаемого к дискуссии и отвечающего стандартам достоверности, верифицируемого и включаемого в научный оборот.

Чисто теоретически оценка в научном дискурсе оказывается институционально предзаданной и отражает общую систему ценностных ориентиров, в основе которых лежат универсальные критерии «научной рациональности» [Ильин 1989: 99-104]. Однако в реальной практике общения оценка выступает как функционально изменчивая категория, наследующая черты варьирующихся по своим целям коммуникативных практик научного дискурса.

Проблемы лингвистической вариативности оценок по формам их выражения, содержанию и функциям в зависимости от коммуникативных параметров научных практик, в которых они используются, не нашли сколько-нибудь последователь- 
ного и эксплицитного освещения в лингвистических исследованиях, в том числе в работах социолингвистической направленности, акцентирующих социальную природу и дискурсивную адресованность оценки. В этой связи задача настоящей статьи состоит прежде всего в том, чтобы представить результаты предварительного анализа употребления оценочных выражений внутри научно-исследовательской, научно-экспертной и научно-обучающей практик. В рамках общего для них научного дискурса указанные практики нацелены на выполнение специализированных, а потому различающихся задач: на представление и обоснование достоверности полученного результата, профессиональную экспертизу предлагаемого нового знания в соответствии с общепринятыми критериями научности, передачу устоявшегося знания с целью обучения основам теоретических дисциплин. Цель той или иной практики наследуется целевым компонентом в содержательной структуре оценки, профилируя последнюю под задачи соответствующей практики. Поэтому меняющиеся целевые установки коммуникативных практик с необходимостью влекут за собой функциональную вариативность лингвистических средств, привлекаемых для оценки научного знания.

\section{Теоретические подходы к изучению оценки}

Оценочность научного текста выдвинулась в фокус внимания лингвистов, начиная с «прагматического разворота» («pragmatic turn») второй половины XX в. Всплеск интереса к оценке и оцениванию в научной коммуникации особенно ощутим в 1980-90-х гг, когда началось интенсивное изучение социально ориентированного употребления профессиональных языков в их соотнесенности с коммуникативными практиками. Новизну этому направлению придают современные ориентиры междисциплинарной лингвистической парадигмы и научные проблемы, решаемые в контексте отношений языка и социума, языка и мышления, языка и культуры. Применительно к категории оценки одной из главных проблем, не нашедших пока системного и полного рассмотрения, является выявление функционально-коммуникативного варьирования языка оценок в разных коммуникативных практиках научного дискурса.

Основная масса работ отечественных авторов обсуждает оценку в общем плане, безотносительно к специфике ее реализации в различных социолингвистических типах дискурса. Если оценка рассматривается в научном дискурсе, то она трактуется как выражение ингерентной черты научной деятельности. При этом констатируется наличие особого оценочного плана в содержании научных текстов: «аксиологического поля» [Котюрова 1988], «субтекста оценки» [Баженова 2001]. Роль оценки и средств ее выражения в структуре познавательной деятельности, в частности при формулировании научного результата, раскрывается через соотнесение речевой структуры научного текста с аксиологической активностью субъектов на основе сопоставления сегментов «старого» и «нового» знания [Данилевская 2013]. Такой подход является логичным продолжением разработки отечественной теории оценки в когнитивно-коммуникативном направлении, поскольку в фокус внимания выдвигается речемыслительная и социокоммуникативная деятельность субъектов познания, вовлеченных в беспрерывный коллективный процесс научного поиска и опирающихся на преемственность в науке. Вместе с тем можно кон- 
статировать здесь наличие не до конца проясненных позиций. В частности, аксиологическая членимость научного текста на сегменты «старого» и «нового» знания представляется слишком общей и требует дальнейшей детализации в соответствии с вектором движения структур знания по эпистемической траектории «верифицируемое - верифицированное - базовое (аксиоматическое) знание».

Зарубежные лингвисты изучают оценку в научной коммуникации преимущественно в рамках различных направлений социолингвистического подхода. Оценка рассматривается при этом как лингвосемиотический ресурс выражения социальных отношений в сфере науки и интерпретируется в контексте профессионального взаимодействия субъектов научного дискурса, ориентирующихся на коллективные, разделяемые всеми представителями академического сообщества нормы и рестрикции. Оценка и оценочные выражения трактуются на уровне семантики текста и дискурса (discourse semantics) как особый инструмент конструирования оценочных значений в межличностной профессиональной коммуникации [Shaw 2004; Hyland 2005]; как функционально-специализированный язык оценивания (evaluative language), позволяющий выразить в научных текстах нюансы авторского позиционирования (stance) по отношению к изучаемому объекту, мнению других исследователей-коллег и собственным утверждениям [Hunston, Thompson 2003; Martin, White 2005; Hood 2010]; как средство интеграции автора-исследователя в профессиональную социальную деятельность и социальную группу с их общими интересами и целями [Reinhart 2010].

Социолингвистические исследования оценки в зарубежной лингвистике одновременно следует считать лингводискурсивными, поскольку дискурс понимается в них как инструмент описания языка на транстекстовом уровне [Чернявская 2021]. Признавая большой вклад социолингвистических и лингводискурсивных исследований в изучение языка оценок и отмечая значительные результаты при интерпретации оценочных выражений на фоне порождающего пространства профессиональной научной коммуникации, следует вместе с тем отметить, что исследователи недостаточно уделяют внимания некоторым важным аспектам оценки, которые обнаруживаются при проецировании языка оценок на разные цели научных коммуникативных практик, разные предметные области науки, меняющиеся роли субъектов дискурса и другие параметры внешней коммуникативной ситуации. В то же время такое направление анализа оценки и оценочных значений представляет несомненный интерес для лингвистики научной коммуникации, так как позволяет выявить и объяснить сбалансированное равновесие между предзаданностью универсальных критериев научности и гибкими коммуникативно-речевыми стратегиями их применения в конкретном тексте. Именно на решение этой задачи нацелена в первую очередь настоящая статья.

\section{Методология и материал лингвистического анализа оценок}

Принятая в работе процедура анализа включает структурную сегментацию текстов на предикации, выделение оценочно заряженных предикаций и рассмотрение употребленных в них оценочных средств на основе прагма-семантических методов, среди которых центральную роль в интерпретации функционального потенциала оценок играют контекстуальные методы. Изучение контекстов употре- 
бления определенных группировок оценочных средств, таких как модальные слова, квалификативные лексемы-номинации оценочных критериев или лексемы важности/центральности, дополняется в исследовании корпусно-ориентированным дискурсивным анализом количественных данных на транстекстовом уровне (подробно об объяснительных возможностях корпусного инструментария дополнительно к лингвистическому см. у В.Е. Чернявской [Чернявская 2019]). В совокупности эти методы представляют комплексную методику, позволяющую выполнить поставленную исследовательскую задачу.

Материалом исследования послужили немецкоязычные корпусы журнальных статей, научных рецензий и вузовских учебников по лингвистике. Первый корпус включает 20 научно-исследовательских статей из ведущих журналов Германии, таких как «Zeitschrift für germanistische Linguistik», «Linguistische Berichte», «Zeitschrift für Germanistik»; он содержит 9900 текстовых предикаций ${ }^{1}$. Второй корпус состоит из 30 рецензий немецких лингвистов, опубликованных в период с 2013 по 2018 г. в онлайн-журнале «Zeitschrift für Rezensionen zur germanistischen Sprachwissenschaft», оперативно размещающем рецензии на монографии отдельных авторов, коллективные монографии, монографии на основе докторских диссертаций. Всего проанализированные рецензии содержат 4252 предикации, из которых 412 предикаций имеют в своем составе средства позитивной оценки, а 311 предикаций - негативной. В третий корпус входят пять современных вузовских учебников, в которых вводятся и объясняют основные теоретические понятия и положения теоретической германистики (Busch A., Stenschke O. Germanistische Linguistik. 2018. 276 S.), лингвистической прагматики (Ernst P. Pragmalinguistik. 2002. 210 S.), интернет-лингвистики (Marx K., Weidacher G. Internetlinguistik. 2014. 236 S.), лингвистики типов текста (Gansel Ch. Textsortenlinguistik. 2011. 128 S.) и текстовоориентированной лингвистики дискурса (Spitzmüller J., Warnke I. Diskurslinguistik. 2011. 236 S.). Последний корпус включает свыше 20 тыс. текстовых предикаций.

\section{Анализ и обсуждение результатов}

Оценка предстает в языке в разном обличьи: как квалификация (теплый прuем, прощальныцй ужин); как модальность знания и мнения (разумеется, конечно, по-видимому, кажется); как авторское позиционирование и комментирование сообщаемого по степени важности, ожидаемости, логичности и т.д. (впервые, важно; отсутствует, недостаток; однако, хотя); как выражение эмоций и чувств (к сожалению, желательно, удивительно, интересно); как градуирование (интенсификация/деинтенсификация) признаков объектов или действий самого речевого субъекта (очень, полностью, совершенно; своего рода, типа, почти). Разные внешние очертания оценки требуют разных языковых форм воплощения. И в этом плане с оценкой не может сравниться никакая другая категория языка. Оценка как гиперкатегория втягивает в свою орбиту многие другие языковые категории: модальность, отрицание, наклонение, градуирование, квантификацию и др. - и переплетается с ними. Все эти категории обнаруживают в своих речемыслительных

${ }^{1}$ Под предикацией при этом понимается двухкомпонентная текстовая структура, воплощающая динамическое развертывание пропозиционального содержания текста и состоящая из предикативно определяемого компонента (субъекта) и предицируемого признака (предиката). 
основаниях, как и оценка, глубинные семантические связи со сравнением. Оценка в буквальном смысле пронизывает все стороны языковой системы и язык в употреблении: лексику, грамматику, текст и транстекстовые структуры - дискурсы. На уровне текста и дискурса оценочные ресурсы языковой системы становятся напрямую зависимыми от контекста и выбора коммуникантов, за которыми стоит экстралингвистическая ситуация и социальная практика с ее типичными акторами и обстоятельствами. Тем самым намеченный концептуальный ряд «оценка текст/дискурс - коммуникативная практика» замыкается, и в фокус внимания попадает центральный тезис настоящей статьи о функциональной вариативности оценок в зависимости от целей коммуникативных практик. Рассмотрим специфику употребления оценок в структуре научно-исследовательской, научно-экспертной и научно-обучающей практик лингвистического дискурса.

\section{Оченка в научно-исследовательской практике}

Основное содержание научно-исследовательской практики задано целью получить новое знание на основе проверенной временем и подтвердившей свою объяснительную силу методики и строгих принципов анализа. В результате должны быть выявлены новые аспекты, связи и закономерности у интересующего исследователей объекта, уточняющие и расширяющие существующую систему научных представлений о нем в данной предметной области. Внутренним двигателем в бесконечном поиске истины в науке становится при этом когнитивный диссонанс в сознании исследователя между наличным и новым знанием. Научный опыт, интуиция и целенаправленная рефлексия над состоянием проблемной зоны, в которую помещается изучаемый объект, в общем виде очерчивают границы и градус конфликта между этими типами знания. Принципиально важно отметить в этом противоборстве «нового» и «старого» два момента. Во-первых, новое знание создается не безликим дисциплинарным сообществом, а конкретным ученым или исследовательским коллективом. Как отмечает Е. А. Баженова, «важнейшим признаком нового знания является его эвристичность и персонифицированность (личностность)» [Баженова 2001: 106]. Во-вторых, чтобы стать предметом последующей дискуссии, новое знание необходимо вербализовать, представить научному сообществу в виде текстового документа: журнальной статьи, монографии, диссертации, автореферата и т. д. Более того, научный результат в виде вербализованного знания транслируется исследователем при полном отсутствии уверенности, что он вообще вызовет профессиональный интерес у других исследователей и тем более после стихийного коллективного обсуждения будет включен в научный оборот соответствующей дисциплины.

Поскольку научная аргументация в принципе строится как обоснование достоверности полученного исследователем результата и базируется на сравнении предлагаемого нового знания с общепринятым знанием или мнением других исследователей, то уже на дотекстовом этапе все утверждения научного текста так или иначе отрефлексированы и соотнесены с системой эпистемических оценок достоверности сообщаемого, выражающей степень познанности объекта, как ее видит познающий субъект. Акты утверждения, таким образом, с неизбежностью сопровождаются актами эпистемического оценивания, т. е. приписывания высказывани- 
ям научного текста модальности достоверности, выражающей субъективно-личностное мнение исследователя об изучаемом объекте. При этом познающий субъект не только наделяет каждое свое высказывание той или иной эпистемической оценкой в соответствии с градуальной шкалой достоверности, варьирующейся в широком модально-оценочном спектре от абсолютной уверенности до сомнения, но и принимает на себя полную «эпистемическую ответственность» за обоснованность приписываемой высказыванию оценки.

Эпистемические оценки как отражение познавательной активности субъекта играют центральную роль в научно-исследовательской практике, поскольку они непосредственно связаны с ее основной целью представить и обосновать новый научный результат на фоне и в сопоставлении с устоявшимся в дисциплине знанием и теоретической позицией других исследователей, т. е. такие оценки непосредственно включены в процесс получения нового знания.

В своей совокупности средства эпистемической оценки образуют функционально-семантическое поле эпистемической модальности, выражающей когнитивные установки знания и мнения говорящего/пишущего [Нефедов 2007]. С лингвистической точки зрения основу этого поля составляют разряды грамматической категории наклонения и широкий класс языковых средств модализации высказывания: модально-эпистемические слова, модальные глаголы, прагматические и градуирующие частицы, конструкции модального инфинитива haben/sein + zu + Infinitiv, глаголы и выражения пропозициональной установки со значением знания и мнения (sich vorstellen, von etwas ausgehen, annehmen, für sinnvoll halten) и целый ряд других средств, выполняющих в контексте научного сообщения функцию эпистемического оценивания. Под модализацией высказывания следует при этом понимать такую речемыслительную операцию, при которой утвердительное (ассертивное) высказывание подвергается семантико-коммуникативной трансформации и приобретает иную иллокутивную значимость, отличную от чистой ассертивности. Иными словами, при модализации высказывания автор-исследователь не сообщает о некотором положении дел как о данности или факте, а сигнализирует адресату, что он включается в обсуждение и представляет соответствующее положение дел в противопоставленности фактам, в модусе контрфактичности только как возможность, необходимость, целесообразность, допущение, альтернативу и т.д. Благодаря модализации автор научного текста меняет угол зрения на утверждаемое, актуализируя тем самым свою теоретическую позицию, и попутно сигнализирует адресату, какую степень достоверности он вкладывает в то или иное утверждение. Выбор средств модализации высказывания маркирует, таким образом, рефлексию автора-исследователя над содержанием сообщаемого. Этот аспект смыслопорождения и смысловосприятия фокусируется в современной метапрагматике, исходящей из базового тезиса о том, что производство и «понимание высказывания должно включать рефлексию над семантикой и прагматикой языковых единиц на основе ситуативного и интертекстуального знания коммуникантов» [Чернявская 2020: 137].

Доминирование эпистемических познавательных оценок, выражающих различное отношение автора-исследователя к достоверности сообщаемых фактов, ожидаемо в научно-исследовательских текстах. Такие оценки позволяют представить решаемую научную проблему и полученные сведения об изучаемом объекте 
в модусе дискуссии, как прогностическое знание, которое еще предстоит коллективно верифицировать, т. е. подтвердить или опровергнуть. Приведем типичный пример текстового фрагмента из изученного корпуса немецкоязычных журнальных статей. Являясь наряду с монографией прототипическим для научно-исследовательской практики типом текста, журнальная статья наиболее наглядно фиксирует в своей речевой структуре особенности аксиологической активности дискурсивных субъектов в этом виде коммуникативной практики. Для удобства анализа текстовые высказывания в приведенном фрагменте (I) пронумерованы.

(I) (1) Das Hauptziel dieser Studie besteht darin, die empirisch vorkommenden syntaktischen Positionsvarianten von übrigens... zu beschreiben. (2) Aus diesen Ergebnissen heraus ergibt sich weiterführend die Frage nach der Funktion und Bedeutung von übrigens. (3) In den bisherigen Studien wird angenommen, übrigens zeige einen plötzlichen Themenwechsel, einen Gedankensprung oder eine Abschweifung an (von Roncador) Bublitz 1985: 285; Altmann 1981: 89, Thim-Mabrey 1985: 92, Helbig, 1988: 225, Paul 1992: $928 f$.). (4) Dieses kann für übrigens im Mittelpunkt nicht als Muster bestätigt werden. (5) Vielmehr scheinen Sprecher/innen es einzusehen, um gemeinsames Vorwissen zu aktivieren... (6) Die Diskrepanz zwischen bisherigen Berichten und den Ergebnissen dieser Studien beruht möglicherweise darauf, dass bisherige Untersuchungen nicht das Wort übrigens an sich als Ausgangspunkt nehmen, sondern es als einen Aspekt in der Abhandlung eines größeren linguistischen Themas analysieren... [Egbert 2002: 2-3] ((1) Основная цель данного исследования состоит в том, чтобы описать эмпирически выявляемые синтаксические варианты позиционного расположения übrigens... (2) Из анализа этих данных следует с необходимостью вопрос о функции и значении ӥbrigens. (3) В прежних исследованиях предполагается, что übrigens маркирует неожиданный поворот темы, скачок в мыслях, отклонение от темы (von Roncador/Bublitz 1985: 285; Altmann 1981: 89, Thim-Mabrey 1985: 92, Helbig, 1988: 225, Paul 1992: 928 f.). (4) Это невозможно подтвердить для ӥbrigens в серединной позиции. (5) Скорее, как кажется, в этом случае говорящие актуализируют общий фонд предварительных знаний... (6) Несоответствие между прежними сведениями и результатами настоящего исследования проистекает, по всей видимости, из того, что прежние исследования рассматривают слово übrigens не само по себе как исходный пункт анализа, а как один из частных вопросов в рамках более широкой лингвистической темы...).

Упомянутая выше типичность приведенного текстового фрагмента вытекает из жанровой специфики журнальной статьи и ее целевого назначения в научно-исследовательской деятельности как типа текста, обслуживающего «передний край науки» [Ильин 1989]. Здесь вербализован характерный для журнальных статей познавательный сценарий, в рамках которого автор-исследователь формулирует свою научную задачу на фоне сделанного предшественниками. При этом он вступает со своими оппонентами в заочную дискуссию и дает оценку достоверности собственным утверждениям и утверждениям коллег, исходя из лично полученных сведений об объекте. Иначе говоря, автор данной статьи М.Эгберт не сообщает в цитируемом фрагменте о подтвержденных фактах, а обсуждает соответствующие положения дел в отношении к научно-теоретической реальности через приписывание им различного эпистемического статуса достоверности и через выражение готовности взять на себя ответственность за достоверность результатов, которые планируется 
получить в будущем. В целом модально-эпистемический план данного текстового фрагмента может быть интерпретирован следующим образом.

В (1) эпистемическая познавательная оценка прямо не выражена, а имплицируется через взаимодействие содержания высказывания, прежде всего его целевой установки, с контекстом. Здесь автор формулирует свою цель, свое стремление получить достоверную информацию в ходе планируемого исследования. На осознанную в деятельности цель (стремление, намерение) всегда накладывается эпистемический компонент уверенности, иначе сама постановка цели лишается смысла. Высказывание (2) подхватывает формулировку задач исследования, ставя обозначенную здесь новую цель в каузальную зависимость от указанных в (1) целей. В следующем высказывании (3) эпистемическая оценка представлена как сомнение автора статьи в обоснованности теоретической позиции перечисленных в ссылке исследователей. Сомнение здесь сначала выражено лексически (wird angenommen), а затем - грамматически, через «цитатный конъюнктив» (Referatskonjunktiv), мapкирующий дистанцированность и неуверенность автора в истинности чужих слов. Высказывание (4) выражает несогласие М. Эгберт (kann nicht bestätigt werden) с выводами указанных в (3) исследователей. В свою очередь, несогласие имплицирует отсутствие достоверности у сделанных прежде утверждений. В (5) автор статьи формулирует собственное мнение по данному вопросу в модусе проблематической (гипотетической) достоверности (vielmehr scheinen Sprecher/innen). Некатегоричное представление собственного мнения - одна из ведущих прагматических стратегий научного дискурса [Нефедов 2017]. Высказывание (6) содержит объяснение причин различий в трактовке значения и функций übrigens у автора статьи и у других исследователей. При этом Эгберт, как и в высказывании (5), использует «рестриктивный (уступительно-ограничительный) модус сдержанного аргументирования на фоне и с учетом ожиданий и ответной оценочной реакции профессионального сообщества» [Нефедов 2017: 607]. Эксплицитным маркером эпистемической оценки здесь служит модально-эпистемическое слово möglicherweise.

Таким образом, эпистемические познавательные оценки образуют в научноисследовательских текстах своего рода семантическую сетку, которая накладывается на каждое без исключения текстовое высказывание. При этом разным частям текста автор-исследователь может приписывать, разумеется, разную оценку степени достоверности утверждаемого, т.е. разную степень соответствия субъективно понимаемой системе достоверных представлений об изучаемом объекте. В градуировании высказываний по степени достоверности участвуют многообразные лексические и грамматические средства, а также средства, получающие модальноэпистемический статус при взаимодействии содержания высказывания с контекстом.

\section{Оценка в научно-экспертной практике}

Коммуникативная практика научной экспертизы выработала специальные типы текстов, сосредоточенные на критической проверке научного результата: отзывы, заключения, рецензии. Такие верифицирующие предлагаемое для дискуссии знание тексты институционально необходимы, так как обеспечивают подтверждение или опровержение полученных результатов и позволяют при положительном 
исходе включить их в научный оборот соответствующей предметной дисциплины. Экспертная работа, таким образом, важна для всего академического сообщества.

Принципиально подчеркнуть некоторые сущностные отличия экспертной оценки от рассмотренной в предыдущем разделе эпистемической познавательной оценки. Самое главное - они различаются в своей концептуальной основе. Или иначе: в их основании лежат разные мотивировки. Эпистемические познавательные оценки реферируют к личному мнению и профессиональному опыту конкретного ученого и допускают широкое, субъективно обусловленное варьирование в рамках градуальной категории достоверности. Они автороцентричны. Напротив, экспертные оценки отсылают к институциональной совокупности общепринятых норм, коллективно установленных научным сообществом для всех случаев активности дискурсивных субъектов и обязательных к соблюдению всеми членами научного профессионального сообщества. Это так называемые универсальные критерии научности, такие как актуальность решаемой задачи, новизна предложенных решений, верифицируемость полученных результатов, логическая непротиворечивость аргументации, точность и ясность изложения и т.д.; см. подробнее: [Ильин 1989; Нефедов 2020]. Иначе говоря, экспертные оценки нормоцентричны.

Из различных концептуальных оснований экспертных и познавательных оценок проистекают их отличительные черты. Основные отличия между ними целесообразно сформулировать в виде следующих аппозитивных пар признаков, из которых первый характеризует экспертную оценку, а второй - эпистемическую познавательную: 1) ориентация оценки на денотаты научно-теоретической реальности, на онтологическую сферу науки, т. е. на то, как наука устроена (объект, предмет, процедуры анализа, материал исследования, язык и стиль изложения и т. д.) vs ориентация оценки на эпистемическую сферу науки, на суждения и мнения других исследователей об изучаемом объекте; 2) точечность оценочного значения vs градуальная вариативность («растянутость») оценочного значения на шкале достоверности; 3) тенденция к эксплицитности выражения оценочных смыслов vs тенденция к имплицитности выражения оценочных смыслов. Это не означает, конечно, что между экспертной и познавательной оценкой воздвигнута непроницаемая преграда, ведь экспертные оценки не лишены субъективности, за которой стоит личное мнение конкретного исследователя, а познавательные оценки, вне всякого сомнения, ориентированы на нормы научной рациональности.

Для выражения экспертных оценок в научных рецензиях по лингвистике задействован широкий спектр оценочных средств. Они достаточно подробно описаны в одной из работ автора настоящей статьи [Nefedov 2019]. Здесь же приведем фрагменты рецензий из исследованного корпуса с общим положительным и негативным профилем, чтобы проиллюстрировать типичные средства и способы выражения экспертно-оценочных смыслов.

(II) Lothar Müller geht es um das Verhältnis von Mündlichkeit und Schriftlichkeit ... In einer scharfsinnigen Auseinandersetzung mit McLuhans Oppositionssetzung... setzt Müller die Vorstellung der wechselseitigen Durchdringung von Mündlichkeit und Schriftlichkeit... Im zweiten Teil des Beitrags gibt er einen aktuellen, historisch situierten Einblick in das Verhältnis von Mündlichkeit und Schriftlichkeit... Dieser Teil ist ein in seiner Prägnanz beeindruckender Überblick über wichtige Stationen der Entwicklung des Zeitungswesens mit Blick auf zeitungstypische Genres. Es folgt im dritten Teil eine ebenso knappe wie 
prägnante Darstellung der Rolle des Internets... [Fix 2017: 140] (У Лотара Мюллера речь идет об отношениях между устной и письменной материальностью текстов... В ходе остроумной дискуссии по поводу оппозиции Маклюэна (имеется в виду известная оппозиция «горячих» и «холодных» СМИ. - С. Н.)... Мюллер формирует представление о взаимном проникновении устного и письменного материального форматов... Во второй части статьи он дает современное, исторически обусловленное понимание отношений между устной и письменной материальностью текстов... Эта часть работы представляет собой впечатляющий по своей точности обзор этапов развития газетного дела с рассмотрением типичных газетных жанров. В третьей части следует сжатое, но четкое описание роли интернета...)

(III) Der Autor erkennt an, dass es sich bei Modifikation um ein primär-semantisches Phänomen handelt, seine basale Modifikatordefinition ist allerdings rein strukturell... Diese Situation erzeugt nicht nur eine grundlegende begriffliche Schieflage (und damit falsche Erwartungen an den Text), sondern auch inhaltliche Probleme. Ein Beispiel: Adjektive werden als modifizierende Wortart bezeichnet, wobei ganz wesentlich auch ihr prädikativer Gebrauch in Kopulastrukturen einbezogen wird. Nach gängigen Annahmen ist direkte Prädikation aber kein Fall von Modifikation, sondern von Argumentsättigung. Dieser Punkt wird im Text nicht behandelt; überhaupt fehlt nahezu jede Auseinandersetzung damit... Der Aufbau der Arbeit ist in mehrfacher Hinsicht nicht zielführend. So stellt Kapitel 3 „Grundsätzliches“ zu Modifikatorenklassen zusammen, ohne dass sich am Ende ein klares Bild vom weiteren Vorgehen ergibt... Zudem ist der Umgang mit dieser Situation aus meiner Sicht unbefriedigend... die Ergebnisse sind entweder sehr grob... oder angesichts der offensichtlichen Klassifikationsprobleme nicht sehr vertrauenswürdig [Bücking 2017: 205]. (Автор признает, что применительно к модификаторам речь идет о примарно семантическом феномене, однако его основополагающее определение модификаторов является чисто структурным... Эта ситуация приводит не только к существенной теоретической ошибке (и тем самым к неверным ожиданиям от текста), но и к проблемам содержательного порядка. Например, адъективы обозначаются как модифицирующая часть речи, при этом в весьма значительном объеме привлекается их предикативное употребление в составе копулятивных структур. Но, согласно общепринятому мнению, прямая предикация является не случаем модификации, а случаем насыщения аргументной структуры. Но эта точка зрения в работе не обсуждается; и вообще практически отсутствует всякая дискуссия по этому поводу... Структура работы во многих отношениях не согласована с поставленной целью. Так, глава 3 представляет «основополагающее» о типах модификаторов, не создавая в итоге ясной картины о дальнейших шагах автора... К тому же, сами решения в этой ситуации неудовлетворительны... Полученные результаты являются либо слишком огрубленными, либо ввиду явных классификационных проблем не вызывают доверия).

В приведенном выше текстовом фрагменте (II) из рецензии известного немецкого лингвиста У.Фикс оценивается один из разделов коллективной монографии, автором которого является Л.Мюллер. Экспертные оценки касаются различных аспектов содержания рецензируемой работы и соотнесены с такими общепринятыми дискурсивными нормами научной деятельности, как актуальность/новизна (aktuell), точность/четкость (prägnant, Prägnanz), обоснованная для обзорно-рефе- 
ративных частей работы краткость изложения (knapp), включенность в историко-научный контекст (historisch situiert). Кроме указанных рациональных оценок, в (2) представлены две эмоциональные позитивные оценки (scharfsinnig, beeindrukkend). Фикс использует здесь языковые средства, типичные для эксплицитного способа выражения экспертно-оценочных смыслов: адъективы, адъективированные причастия, абстрактные существительные качественно-характеризующей семантики.

Что касается фрагмента (III), то он, как и вся рецензия немецкого лингвиста С. Бюкинга в целом, содержит отрицательную оценку представленного научного результата. Здесь задействован целый спектр эксплицитных средств негативного оценивания: отрицание nicht и отрицательный префикс un- в соединении с эксплицитно-оценочными лексемами, обозначающими несоответствие дискурсивной нормы (nicht zielführend, nicht vertrauenswürdig, unbefriedigend); отрицательный союз ohne dass, представляющий именуемое в предложении положение дел как отсутствующее, что также не соответствует институциональной норме (ohne dass sich ein klares Bild ergibt); общеоценочная лексема falsch со значением 'ложный, неверный, недостоверный'; абстрактные существительные с негативной аксиологической полярностью Schieflage, Problem. Кроме того, в первом текстовом высказывании данного фрагмента негативная экспертная оценка выражается имплицитно, через информирование; об импликации оценки через констатацию фактов в их соотнесенности со стандартами научно-исследовательской деятельности (по формуле «этого нет, но должно быть») см. подробнее [Nefedov 2019: 1877]. Рецензент сообщает здесь об установленном факте, но подразумевает его оценку, так как данный факт вступает в противоречие с общепринятой научной нормой: автор монографии декларирует один подход (семантический), а на практике реализует другой - структурный. Еще один способ импликации негативной оценки обнаруживается в связи с употреблением предикативного отрицания nicht при предикате behandeln (Dieser Punkt wird im Text nicht behandelt) и имплицитно-отрицательного предиката fehlen (...fehlt nahezu jede Auseinandersetzung). В обоих случаях применяется стратегия показа ситуации «от обратного» [Nefedov 2019: 1879]. В результате отсутствие чеголибо в рецензируемой работе интерпретируется в контексте научной деятельности как отклонение от нормы, а значит - как негативное.

Таким образом, оценивая различные аспекты содержания научной работы, процедуру и материал анализа, язык и стиль изложения, рецензент как субъект дискурса, профессионально занимающийся научно-исследовательской и экспертной деятельностью, руководствуется своим личным опытом и своими знаниями об общепринятых критериях, предъявляемых к научному результату. Абсолютные критерии научности составляют систему тех универсальных ценностей, в системе которых выносятся позитивные и негативные экспертные оценки.

\section{Оценка в научно-обучающей практике}

Трансфер устоявшегося в той или иной предметной дисциплине знания требует особых форм и средств оценивания. В научно-обучающей практике в целом и практике обучения основам теоретических дисциплин в частности оценка служит главной цели - акцентированию наиболее важных элементов вербализуемого 
знания. Учебное знание должно быть как минимум предварительно верифицировано и признаваться научным сообществом в качестве достоверного на текущий момент. Поскольку оценивание осуществляется по параметрам важности, весомости, значимости, то соответствующие оценки выполняют в коммуникации между педагогом - автором учебника и обучающимся убеждающе-воздействующую функцию. Соответственно, предлагается именовать такого рода оценки персуазивными. Персуазивные оценки структурируют общий информационный поток теоретически ориентированного учебника на структурные элементы и привлекают внимание обучающегося к наиболее значимым его частям. Тем самым оценка в вузовском учебнике воплощает в себе направленность на адресата и выражает желание ученого-педагога воздействовать на сознание обучающего, изменяя запас его предметных теоретических знаний.

Оценки в структуре научно-обучающей практики в значительной степени адресатоцентричны. Они направлены на то, чтобы структурировать информацию в тексте и управлять вниманием реципиента. Кроме того, в вузовском учебнике оценки элементов дисциплинарного знания по степени информативной весомости уже в дотекстовой фазе отрефлектированы более опытным ученым-исследователем с целью оптимизации передачи знаний.

В качестве индикаторов персуазивной оценки в научно-учебном дискурсе используются разноструктурные языковые средства: адъективы с семантикой смысловой переднеплановости zentral, wichtig, führend, wesentlich, bedeutend, bedeutsam, bedeutungsvoll, relevant, maßgeblich; сходные по смыслу с указанными адъективами предложно-субстантивные выражения im Zentrum, im Mittelpunkt, von großer Bedeutung, im Wesentlichen; композиты с компонентами Haupt- (Hauptproblem, Hauptteil, Hauptaufgabe), Kern- (Kernfrage, Kernfragestellung), Grund- (Grundgedanke, Grundthematik, Grundtheorie); градуирующие интенсифицирующие частицы sehr, zu, ziemlich, recht и функционально подобные им интенсификаторы insbesondere, besonders, namentlich, hauptsächlich, vor allem, in erster Linie; глаголы ментальных действий с семантикой выделения/подчеркивания betonen, auf etwas hinweisen, unterstreichen и т. п.; коннекторно-связующие слова с семантикой интенсификации, эксплицирующие речемыслительную операцию добавления существенного элемента информации: außerdem, überdies hinaus, zudem, ferner, und auch и т. д. Приведем примеры использования данных средств в контекстах научно-учебной коммуникации.

(IV) Sprachlichem Handeln, dem Handeln mit und durch Sprache, liegen offenbar dieselben Kriterien zu Grunde... Ein zentraler Begriff dabei ist jener der Kommunikation. Ohne hier genauer auf diverse Kommunikationsmodelle... eingehen zu können, stellen wir lediglich fest, dass sprachliches Handeln das Interagieren zwischen mehreren Personen mit dem Mittel der Sprache bedeutet. Daraus wird aber auch deutlich, dass Sprache als wesensidentisch mit sprachlichem Handeln erscheint und dieses nicht einfach nur als Folge von sprachlichen Äußerungen zu betrachten ist: Auch mit sprachlichen Äußerungen intendieren wir etwas, bewirken wir etwas und richten uns an Interaktionspartner. Es wurde mit Recht darauf hingewiesen, dass Handeln und damit auch sprachliches Handeln nur in Interaktion mit Wissen möglich ist... [Ernst 2002: 26] (В основу выделения речевых действий, действий с и посредством языка, положены, по-видимому, те же самые критерии... Центральное понятие здесь - это понятие коммуникации. Не имея здесь возможности подробнее рассмотреть различные модели комму- 
никации..., отметим только, что речевое действие означает интеракцию между несколькими индивидами при помощи языка. Из этого становится понятным, что язык выступает как феномен, идентичный по своей сути речевой деятельности, а речевую деятельность не следует рассматривать только как последовательность языковых высказываний: и с помощью языковых высказываний мы реализуем какие-то намерения, совершаем что-то и обращаемся к партнеру по интеракции. Было справедливо указано, что деятельность и, тем самым, речевые действия возможны только во взаимодействии со знанием...).

(V) Für den folgenden Abschnitt ist es wichtig festzustellen, dass in der Textlinguistik durchaus gesehen wird, dass der Funktionsbegriff uneinheitliche Parameter impliziert. Dies zeigt sich darin, dass in unterschiedlichen textsortenlinguistischen Modellierungen die Textfunktion/kommunikative Funktion einmal als textinternes Merkmal, dann als textexternes Merkmal oder auch als beides charakterisiert wird. Diese Unsicherheit gilt es aufzulösen und so soll im Folgenden herausgearbeitet werden, worauf der Begriff >Funktion im Zusammenhang mit Textsorten bezogen werden kann.

Zunächst können wir festhalten, dass die textinterne dominante Textfunktion... [Gansel 2011: 68].

(Для следующего раздела важно отметить, что в лингвистике вполне принимается тезис о том, что понятие функции предполагает учет разнородных параметров. Это проявляется в том, что в различных лингвистических моделях типов текста функция текста/коммуникативная функция характеризуется то как внутритекстовый признак, то как внешнетекстовый признак или же по обоим признакам. Эту неопределенность следует устранить, и в дальнейшем изложении будет разработана позиция относительно того, к чему можно прилагать понятие функции в связи с обсуждением типов текста.

Изначально мы можем исходить из того, что внутритекстовая доминантная функция...)

В приведенных текстовых фрагментах из учебника по лингвистической прагматике П.Эрнста (IV) и учебного пособия по лингвистике типов текста К. Ганзель (V) представлены три основных типа средств с персуазивно-оценочной функцией. Это, во-первых, адъективы с семантикой важности/центральности: wichtig, zentral. Во-вторых, в текстовых извлечениях используются конструкции с глаголами ментальной деятельности, обозначающие интеллектуальную обработку авторами учебников сообщаемого по степени важности и выделение/подчеркивание наиболее информативно весомых элементов информации: feststellen 'отметить, заметить', deutlich werden 'становиться понятным', auf etwas hinweisen 'отмечать что-либо, указывать на что-либо', sich zeigen 'проявляться в чем-либо'. И наконец, в-третьих, важность соответствующих фрагментов информации выражается косвенным образом, за счет применения имплицитно-побудительных структур, стимулирующих адресата к сотрудничеству, поскольку это важно для получения необходимых знаний по обсуждаемой проблеме: Diese Unsicherheit gilt es aufzulösen..., Zunächst können wirfesthalten, dass... Два последних типа средств с персуазивно-оценочной функцией имеют, как это нетрудно заметить, метатекстовый комментирующий характер. Через оценку важности передаваемой информации они удерживают и направляют внимание адресата. 


\section{Заключение}

Примененная дискурсивно-аналитическая методология и корпусная процедура анализа позволили выявить особенности употребления оценочных средств на транстекстовом уровне, представляющим языковой срез коммуникативных практик научного лингвистического дискурса / его функциональных разновидностей. Выявлено функционально-коммуникативное варьирование языка оценок в зависимости от коммуникативных установок научно-исследовательской, научно-экспертной и научно-обучающей коммуникативных практик. Указанные практики нацелены, соответственно, на представление и обоснование научного результата как дискутируемого знания; его профессиональную экспертизу на соответствие/ несоответствие общепринятым критериям научной достоверности (истинности); трансфер коллективно верифицированного знания при обучении основам теоретических дисциплин. Установлено, что разные целевые установки коммуникативных практик и разная адресация дискурса влияют на средства и способы выражения оценочных смыслов. Каждая коммуникативная практика имеет свой собственный оценочный язык.

В научно-исследовательской практике язык оценок автороцентричен. Он отражает персонифицированное мнение конкретного исследователя, которое выражается в контексте противоборства «старого» знания с «новым» знанием, в контексте согласия или несогласия с мнением других исследователей. Обосновывая в ходе научной дискуссии личную теоретическую позицию на изучаемую проблему, ученый-исследователь сопровождает каждый акт утверждения эпистемическим оцениванием - приписыванием текстовым высказываниям эпистемического статуса, или - в терминах лингвистики - эпистемической модальности достоверности. Благодаря этому автор научного текста распределяет сообщаемое на градуальной шкале по степени субъективно понимаемой достоверности. Автороцентричности научно-исследовательской практики и стоящих за ней текстов соответствует особый язык оценок - язык модально-эпистемических компонентов, модальных глаголов, форм наклонения и других модализирующих содержание высказывания средств.

Оценочный язык в научно-экспертной практике нормоцентричен. Он отражает степень соответствия оцениваемого экспертом результата институциональным критериям научности - общепринятой системе универсальных ценностей, предъявляемых к научной деятельности и научному результату. Экспертный язык оценок представлен в своей основе качественно-квалифицирующими лексемами: адъективами, адъективированными причастиями, nomina qualitatis. Данные средства оценки реферируют к системе коллективных научных ценностей и устанавливают соответствие/несоответствие им по качеству научного результата, использованных процедур и методов, языка и стиля изложения и т.д. Анализ корпуса экспертных текстов выявляет, кроме того, широкую распространенность имплицитных способов выражения оценок на фоне взаимодействия содержания высказывания с контекстом научной деятельности - с профессиональным знанием ученого о дискурсивных нормах.

Своеобразие языка оценок в научно-обучающей практике заключается в его адресатоцентричности. В инсценируемом общении ученого-педагога и обучаю- 
щегося фактор адресации дискурса задает семантический и структурный диапазон языка оценок. Стремление автора учебника донести до целевого адресата необходимое ему знание в эффективной и структурированной форме требует комментирования и ранжирования элементов вербализуемого знания по степени их важности, значимости, центральности. Поэтому оценочный язык в вузовском учебнике предстает в значительной степени в обличии языка метатекстовой навигации, в форме структур и лексических единиц с функцией выделения/подчеркивания, адъективов, предложно-субстантивных групп и композитов с семантикой переднеплановости/центральности и других средств фокусирования информативно весомых элементов дисциплинарного знания, предлагаемого обучающемуся для усвоения.

Аллюзия на центральный тезис в предпосланном статье эпиграфе - известном высказывании Н. Д. Арутюновой о языковой оценке [Арутюнова 1988: 6] - становится, таким образом, воплощенной дискурсивной реальностью бытования языка оценок. Названные здесь мотивы оценки обнаруживают метафорическую связь с коммуникативными установками проанализированных практик употребления оценок в функциональных разновидностях научного дискурса: «желание» допустимо интерпретировать как стремление конкретного исследователя внести свой личный вклад в науку (определенную дисциплинарную область), чтобы подтвердить профессиональную компетентность и приобрести определенный авторитет среди коллег; «долг» - как обязанность всех представителей академического сообщества брать на себя функции эксперта, чтобы быть включенным в беспрерывный коллективный процесс поиска истины; «нужду» - как необходимость ученого делиться знаниями с подрастающим поколением исследователей, чтобы связь между настоящим и будущем не прерывалась.

\section{Источники}

Egbert 2002 - Egbert M. Syntaktische Merkmale von übrigens in der Hauptposition: im Mittelfeld des Verb-Zweit-Satzes. Zeitschrift für germanistische Linguistik. 2002, (30): 1-22.

Ernst 2002 - Ernst P. Pragmalinguistik. Grundlagen. Anwendungen. Probleme (de Gruyter Studienbuch).

Berlin; New York: de Gruyter, 2002. 210 S.

Gansel 2011 - Gansel Ch. Textsortenlinguistik. Göttingen: Vandenhoeck \& Ruprecht. 2011. 128 S.

Fix 2017 - Angemessenheit. Einsichten in Sprachgebräuche (Valerio 18). Göttingen: Wallstein. 180 S. Fix U. J. Sch. (Hg.). Zeitschrift für Rezensionen zur germanistischen Sprachwissenschaft. 2017, 9 (1-2): 136143.

Bücking 2017 - Bücking S. Hagen Hirschmann. (2015). Modifikatoren im Deutschen. Ihre Klassifizierung und varietätenspezifische Verwendung (Studien zur deutschen Grammatik 89). Tübingen: Stauffenburg. 304 S. Zeitschrift für Rezensionen zur germanistischen Sprachwissenschaft. 2017, 9 (1-2): 203-208.

\section{Литература}

Арутюнова 1988 - Арутюнова Н.Д. Типы языковых значений: Оиенка. Событие. Факт. М.: Наука, 1988. $341 \mathrm{c}$.

Арутюнова 1999 - Арутюнова Н.Д. Оценка в механизмах жизни и языка. В кн.: Арутюнова Н.Д. Язык и мир человека. М.: Языки русской культуры, 1999. С. 130-274.

Баженова 2001 - Баженова Е. А. Научный текст в аспекте политекстуальности. Пермь: Изд-во Перм. гос. ун-та, 2001. 269 с. 
Данилевская 2013 - Данилевская Н. В. Об особом статусе оценки в научном тексте. Вестник Пермского государственного университета. 2013, 2 (22): 37-43.

Ильин 1989 - Ильин В. В. Критерии научности знания. М.: Высшая школа, 1989. 127 с.

Котюрова 1988 - Котюрова М.П. Об экстралингвистических основаниях смысловой структурынаучного текста. Красноярск: Изд-во Краснояр. ун-та, 1988. 171 с.

Нефедов 2007 - Нефедов С. Т. Коммуникативная модальность и эпистемические модальные компоненты в немецком языке (синхрония и диахрония). Филиппов К. А. (ред.). СПб.: Изд-во С.Петерб. ун-та, 2007. 199 с.

Нефедов 2017 - Нефедов С. Т. Рестриктивная аргументация: модальные слова сомнения и общезначимости (на материале немецкоязычных лингвистических статей). Вестник СанктПетербургского университета. Язык и литература. 2017, 14 (4): 599-610.

Нефедов 2020 - Нефедов С. Т. Социокоммуникативное измерение оценки. Германистика в современном научном пространстве. Материалы VI Международной научно-практической конферениии. Краснодар, 2020. С. 122-128.

Нефедов, Чернявская 2020 - Нефедов С. Т., Чернявская В.Е. Контекст в лингвистическом анализе: прагматическая и дискурсивно-аналитическая перспектива. Вестник Томского государственного университета. Филология. 2020, (63): 83-97.

Чернявская 2019 - Чернявская В. Е. Корпусно-ориентированный дискурсивный анализ идентичности российского университета 3,0 . Вестник Томского государственного университета. Филотогия. 2019, (58): 97-114.

Чернявская 2020 - Чернявская В.Е. Метапрагматика коммуникации: когда автор приносит свое значение, а адресат свой контекст. Вестник Санкт-Петербургского университета. Язык и литература. 2020, 17 (1): 135-147.

Чернявская 2021 - Чернявская В.Е. Текст и социальный контекст: Социолингвистический и дискурсивный анализ смыслопорождения. М.: Ленанд, 2021. 208 с.

Gansel et al. 2019 - Gansel Ch., Nefedov S., Jesan I. Zu Aspekten der Darstellung kommunikativer und sprachlicher Praktiken. In: Kommunikative Praktiken in sozialen Kontexten: Sprachliche Mittel im Einsatz. Gansel Ch., Nefedov S., Jesan I. (Hrsg.). (Reihe: Projekt Angewandte Linguistik. Bd. 3). Münster; Berlin; London: LIT-Verlag. 2019. S. 1-9.

Hood 2010 - Hood S. Appraising Research: Evaluation in Academic Writing. New York: Palgrave Macmillan, 2010. XI $+227 \mathrm{p}$.

Hunston, Thompson 2003 - Hunston S., Thompson G. Evaluation in Text. Authorial Stance and the Construction of Discourse. Oxford: Oxford University Press, 2003. 225 p.

Hyland 2005 - Hyland K. Stance and engagement: a model of interaction in academic discourse. Discourse Studies. 2005, 7 (2): 173-192.

Martin, White 2005 - Martin J. R., White P. R. R. The Language of evaluation. New York: Palgrave Macmillan, 2005. XII $+278 \mathrm{p}$.

Nefedov 2019 - Nefedov S.T. Towards evaluation in scientific reviews (based on German linguistics). Journal of Siberian Federal University - Humanities and Social Sciences. 2019, 12 (10): 1868-1886.

Nefedov 2020 - Nefedov S. T. Wort-, Textsatz- und Diskurssemantik des Lexems Kontext. Sprache \& Sprachen. Sonderheft: Deutsch-russische diskursive Zusammenhänge. 2020, (51): 29-42.

Reinhart 2010 - Reinhart M. Peer Review Practices: Epistemic and Social Aspects in the Assessment of Scientific Work. Research Evaluation. 2010, 19 (5): 317-331.

Shaw 2004 - Shaw P. How do we recognize implicit evaluation in academic book reviews? In: Academic Discourse: New Insights into Evaluation. Del Lungo Camiciotti G., Tognini Bonelli E. (eds). Amsterdam: Peter Lang. 2004. P. 121-140. 
St. Petersburg State University,

7-9, Universitetskaya nab., St. Petersburg, 199034, Russia

s.nefedov@spbu.ru

\section{The variety of evaluation in communicative practices of academic discourse}

For citation: Nefedov S.T. The variety of evaluation in communicative practices of academic discourse. Vestnik of Saint Petersburg University. Language and Literature. 2021, 18 (4): 760-778. https://doi.org/10.21638/spbu09.2021.408 (In Russian)

The article represents a discourse-analytical and corpus study of the evaluation of language as a pragmatic tool in the structure of the professional scientific activity of German linguists. The aim of the work consists in outlining the functional-communicative variety of the evaluation language, depending on the principal task of scientific research, scientific expert and scientific-educational communication practices. The scholarly relevance of the research rests on its incorporation into modern interdisciplinary studies of language resources from the aspect of linguistic pragmatics, interactional sociolinguistics and discourse linguistics, which are directed, on the whole, towards the study of the language and interpretation of the meaning of language signs within the framework of real social contexts while also taking into account a wide range of extralinguistic factors. The novelty of the research is evident in the following results: for the first time, the linguistic variety of evaluations dependent on the general aim of communication practice, which determines the axiological perspective, is considered; a disciplinary correlated classification of evaluation with the allocation of epistemic cognitive, expert and persuasive evaluation is proposed; the essential differences between the selected types of evaluation in the pragmatic categories of author-centricity, normo-centricity and addresseecentricity are substantiated; the text- and discourse-forming part played by language markers of the evaluation category of importance/relevance in profiling and promoting established knowledge in the process of teaching the fundamental theoretical disciplines is revealed. The research material was the German-language corpus of journal articles, scientific reviews and university textbooks on linguistics.

Keywords: evaluation, academic discourse, epistemic cognitive evaluation, expert evaluation, persuasive evaluation.

\section{References}

Арутюнова 1988 - Arutiunova N. D. Types of linguistic meaning: Evaluation. Event. Fact. Moscow: Nauka Publ., 1988. 341 p. (In Russian)

Арутюнова 1999 - Arutiunova N.D. Evaluation into the mechanisms of life and language. In: Arutiunova N. D. Iazik i mir cheloveka. Moscow: Iazyki russkoi kultury Publ., 1999. P. 130-274. (In Russian)

Баженова 2001 - Bazhenova E. A. Scientific text in the aspect of polytextuality. Perm: Izdatel'stvo Permskogo gosudarstvennogo universiteta Publ., 2001. 269 p. (In Russian)

Данилевская 2013 - Danilevskaia N.V. On the special status of evaluation in a scientific text. Vestnik Permskogo gosudarstvennogo universiteta. 2013, 2 (22): 37-43. (In Russian)

Ильин 1989 - Iliin V. V. Criteria for the scientific knowledge: Monograph. Moscow: Vysshaia shkola Publ., 1989. 127 p. (In Russian)

Котюрова 1988 - Kotiurova M. P. Towards extralinguistic foundations of the meaning structure of a scientific text. Krasnoiarsk: Izdatel'stvo Krasnoiarskogo Universiteta Publ., 1988. 171 p. (In Russian)

Нефедов 2007 - Nefedov S.T. Communicative modality and epistemic modal components in German (synchrony and diachrony), Filippov K. A. (ed.). St. Petersburg.: St. Petersburg University Press, 2007. 199 p. (In Russian) 
Нефедов 2017 - Nefedov S. T. Restrictive argumentation: modal words of doubt and shared knowledge in academic linguistic writings. Vestnik of Saint Petersburg University. Language and literature. 2017, 14 (4): 599-610. (In Russian)

Нефедов 2020 - Nefedov S. T. Socio-communicative dimension of evaluation. In: Germanistika v sovremennom nauchnom prostranstve. Materialy VI Meshdunarodnoi nauchno-prakticheskoi konferentsii. Krasnodar, 2020. P. 122-128. (In Russian)

Нефедов, Чернявская 2020 - Nefedov S.T., Chernyavskaya V.E. Context in linguistics: Pragmatic and Discourse Analytical Dimensions. Vestnik Tomskogo Gosudarstvennogo Universiteta. Filologiia. 2020, (63): 83-97. (In Russian)

Чернявская 2019 - Chernyavskaya V.E. Corpus-Assisted Discourse Analysis of Russian University 3,0 Identity. Vestnik Tomskogo gosudarstvennogo universiteta. Filologiia. 2019, (58): 97-114. (In Russian)

Чернявская 2020 - Chernyavskaya V.E. Metapragmatics: When the author brings meaning and the addressee context. Vestnik of Saint Petersburg University. Language and literature. 2020, (1) (17): 135147. (In Russian)

Чернявская 2021 - Chernyavskaya V.E. Text and social context: Sociolinguistic and discourse analysis of meaning generation. Moscow: Lenand Publ., 2021. 208 p. (In Russian)

Gansel et al. 2019 - Gansel Ch., Nefedov S., Jesan I. Zu Aspekten der Darstellung kommunikativer und sprachlicher Praktiken. In: Kommunikative Praktiken in sozialen Kontexten: Sprachliche Mittel im Einsatz. Gansel Ch., Nefedov S., Jesan I. (Hrsg.). (Reihe: Projekt Angewandte Linguistik. Bd. 3). Münster; Berlin; London: LIT-Verlag. 2019. P.1-9.

Hood 2010 - Hood S. Appraising Research: Evaluation in Academic Writing. New York: Palgrave Macmillan, 2010. XI $+227 \mathrm{p}$.

Hunston, Thompson 2003 - Hunston S., Thompson G. Evaluation in Text. Authorial Stance and the Construction of Discourse. Oxford: Oxford University Press, 2003. 225 p.

Hyland 2005 - Hyland K. Stance and engagement: a model of interaction in academic discourse. Discourse Studies. 2005, 7 (2): 173-192.

Martin, White 2005 - Martin J. R., White P. R. R. The Language of evaluation. New York: Palgrave Macmillan, 2005. XII $+278 \mathrm{p}$.

Nefedov 2019 - Nefedov S. T. Towards evaluation in scientific reviews (based on German linguistics). Journal of Siberian Federal University - Humanities and Social Sciences. 2019, 12 (10): 1868-1886.

Nefedov 2020 - Nefedov S. T. The word, sentence, text and discourse semantics of the lexeme Kontext 'context'. Sprache \& Sprachen. Sonderheft: Deutsch-russische diskursive Zusammenhänge. 2020, (51): $29-42$.

Reinhart 2010 - Reinhart M. Peer Review Practices: Epistemic and Social Aspects in the Assessment of Scientific Work. Research Evaluation. 2010, 19 (5): 317-331.

Shaw 2004 - Shaw P. How do we recognize implicit evaluation in academic book reviews? In: Academic Discourse: New Insights into Evaluation. Del Lungo Camiciotti G., Tognini Bonelli E. (eds). Amsterdam: Peter Lang. 2004. P. 121-140.

Received: December 15, 2020

Accepted: September 13, 2021 